\title{
'The more you go to the mountains, the better parent you are'. Migrant parents in Norway navigating risk discourses in professional advice on family leisure and outdoor play
}

\author{
Raquel Herrero-Arias a, b, *, Ellie Lee ${ }^{\mathrm{c}, \mathrm{d}} \&$ Ragnhild Hollekim ${ }^{\mathrm{a}, \mathrm{b}}$ \\ ${ }^{a}$ Department of Health Promotion and Development, Faculty of Psychology, University of Bergen, \\ Norway. \\ ${ }^{b}$ Child Welfare, Equality, and Social Inclusion Research Group, University of Bergen, Norway. \\ ${ }^{c}$ Social Policy, Sociology and Social Research, University of Kent, Canterbury, UK. \\ ${ }^{d}$ Centre for Parenting Culture Studies, University of Kent, Canterbury, UK.
}

\begin{abstract}
Drawing on data from a study with Southern European parents living in Norway, this article discusses the experiences of migrant parents with professional advice on family leisure and outdoor play. The study is situated broadly in research about the contemporary parenting role and the social construction of parents as risk-managers. Within this construction, parents are understood as continually managing a 'double-bind', in which they are asked to both protect children from multiple risks, and expose them to risk to develop resilience. Norway provides an interesting context for further investigation, given its institutionalised emphasis on the importance of outdoor life and play. This is embedded in public provision for children and in dominant understandings of how families should use leisure time and how children should play. We explore how migrant parents respond to the associated discourses of risk in their encounters with kindergarten professionals and community health nurses. Participants navigated risk discourse in professional advice on family leisure and children's outdoor play in three ways: contesting discourses of risk; feigning cooperation; and accepting professional intervention and advice in either collaborative or compliant relationships. Migrant parents experienced professional constructions of risk-management as implying a form of individual responsibility, which typically recognized risks to children's wellbeing linked with their lifestyle choices. Although some found ways to negotiate risk and accommodate, parental experience was characterised by tension and difficulties in encountering the double-bind, which deserves further attention.
\end{abstract}

Key Words Migrant parents, Norway, risk management, professional advice, double bind, family leisure

*Corresponding author. Email: Raquel.Arias@uib.no 


\section{Introduction}

In this article we explore the experiences of twenty Southern European migrant parents living in Norway; specifically, in their encounters with community health nurses (helsesøstre) and kindergarten professionals, discussing outdoor play and family leisure. Because of its institutionalised emphasis on the importance of outdoor life and developing resilience, we see Norwegian professional practices as an appropriate site in which to explore how parents navigate a double-bind position, trying to reconcile contrasting demands on their role as risk-managers. The experience of migrant parents constitutes an especially salient focus for such research, given their position as people with experience of alternative cultural framings of risk and as people particularly subject to professional advice about Norwegian understandings of what children need. A central argument developed in this paper is that migrant parents experienced professional constructions of risk-management as implying a form of individual responsibility for their lifestyle choices associated with Southern European cultures.

Parenting culture is fundamental for the development of risk consciousness (Lee et al., 2010). In this regard, in this study we contribute to the field of critical studies of risk, through a focus on parents' experiences with the institutionalization of approaches to uncertainty that are grounded in adults' confusions regarding moral values and attitudes towards the socialization of children (Furedi, 2008). We argue that Bateson's concept of double-bind provides a conceptual tool for capturing the experiences of migrant parents balancing irreconcilable demands on their parenting in their encounters with professionals. This knowledge can bring a better understanding of how risk is understood and managed, and the tensions in the experience of migration.

The contemporary parenting role has been widely described as 'intensive'; as the frequently cited summary from Hays puts it, raising children has been constituted as an activity that is, "child- 
centred, expert-guided, emotionally absorbing, labour intensive and financially expensive" (Hays, 1998, p. 9). The literature has connected intensive parenting to the wider phenomenon of riskaversion and risk consciousness. It shows how responsible parenting implies a construction of parents as "having a moral and social responsibility to be risk conscious" (Knaak, 2010, p. 345). Intensive parents are managers of risk, open to being made aware of, and responding to, information about an increasing number of risks impacting child development and well-being (Furedi, 2008; Lee, 2014).

This perspective becomes apparent in professional and policy discourse, in which parents are simultaneously considered inadequate risk-managers who therefore need expert guidance (Furedi, 2008; Lee, 2008). Institutional practices have been critiqued for overlooking structural conditions and focusing more on identifying families "at risk" and targeting professional intervention at them, contributing to othering processes (Montelius \& Nygren, 2014). Such risk constructions have a moral component that implies that "responsible" individuals are expected to self-regulate according to middle-class norms. This has been particularly explored in health promotion practices that, framed by a lifestyle ideal of healthy living, identify families and children "at risk" based on notions of "legitimate" risks related to lifestyle choices, like unhealthy diet or tobacco (Aamann \& Dybbroe, 2018).

Intensive parenting is thus considered consonant with neoliberal notions of individual responsibility and professionalised risk-management. Within this construction, however, attention has recently been paid to a context in which the parental role (and parental failings) are identified in the requirement that parents protect their children from multiple risks, but also that parents simultaneously expose children to risk, in order to develop resilience. To capture a position in which parents encounter contradictory demands on their role as risk-managers, authors have used the notion 
of the "double-bind" (Bristow, 2014). Bateson defined this concept as a position in which a person is confronted by contradictory messages, with one negating the other, so that the successful response to one of them involves a failed response to the other (Bateson et al., 1956). According to Bateson, such a distressing and ambiguous position arises in relationships of great importance, typically characterized by respect and/or dependence, in which the person cannot leave the interaction and opt out of the dilemma (Bateson, 1972). The double-bind of intensive parenting culture is underpinned by a construction of childhood around an emphasis on safety and protection, together with a growing attention to resilience, which is presented in parenting advice literature as "the antidote to risk" (Hoffman, 2010, p. 392). Parents are thus warned of the need to be attentive to risks to children whose health, well-being and development they must never neglect, but are also accused of being "helicopter parents" who harm their children and impair the development of resilience through overparenting (Bristow, 2014; Lee et al., 2010).

\section{Outdoor play and family leisure: Norwegian discourses on children and parenting}

Intensive parenting includes a preoccupation with family leisure and attendant debates about whether this contributes to children's development (Allin, West, \& Curry, 2014). As Shaw and Dawson (2008; 2001) discussed, current understandings of family leisure have a purposive and moral nature. As well as being characterized by free-choice and enjoyment, family leisure is constructed as part of the parental role. Parents are expected to plan, organize, and perform activities that are safe for children, but also impart positive values, promote healthy lifestyles, and nurture family cohesion, so that their children will become good adults, parents, and citizens. This message has become stronger through popular media and public policy's campaigns against health risks of sedentariness (Fullagar \& Harrington, 2009; Gard \& Wright, 2005). 
Outdoor activities are promoted as a site for learning skills and values, and as a space for practices that develop children's creativity and resilience (Brussoni et al., 2015). This can be seen in institutions like kindergartens, which have adopted educational approaches towards nature-based outdoor learning. Forest schools are encouraged as they centre on activity in nature and involve children engaging in something unfamiliar (Sandseter, Little, \& Wyver, 2012). This is supported by the assumption that outdoor play contributes to children's healthy development, risk-management and learning of social skills and democratic values (Aasen, Grindheim, \& Waters, 2009).

While the explicit promotion of the outdoors as part of childhood by official agencies may be new to some Western societies, it is well-known that nature has a special value in Norway (Guldberg, 2009). The philosophy of friluftsliv, or outdoor lifestyle, is a taken-for-granted key symbol of the culture and national identity (Gullestad, 1997). Its origins come from the old Scandinavian harvesting lifestyle and the bourgeois romantic ideas of contact with nature as a reaction against urbanization and industrialization, which became important elements for the Norwegian nation-building (Dervo et al., 2014). Nature became a meaningful ideal with which Norwegians identify emotionally through the construction of a self-image of "nature-loving people" (Sandell \& Sörlin, 2000). Friluftsliv can be understood as an ideological narrative because of the moral values and social discourses attached to it (Pedersen Gurholt, 2008). It draws a boundary between Norwegians and non-Norwegians acting as a tool for educating individuals into good (Norwegian) citizens (Dervo et al., 2014).

Nature and the outdoors are also at the core of Norwegian constructions of "good" parenting and childhood. Framed by discourses of worry and of the rights of the child, dominant constructions of childhood in Norway contain the notion of a "robust child", who is independent, rational and grows up in an unspoiled environment (Nilsen, 2008). This childhood ideal reflects middle-class 
values that are present in outdoor activities and emphasized in the Norwegian culture, like independence, agency, and participation (Hollekim et al., 2016). Outdoor play is an important component of childhood in Scandinavia through which children can engage in children-directed activities (Gullestad, 1992, 1997). The benefits of experiencing various weather conditions, managing risks, and developing spatial skills through outdoor play are recognized in Norwegian media discourses, policies, and institutional practices (Sandseter et al., 2012).

Documents including the Kindergarten Act and the Norwegian Framework Plan for the Content and Tasks of Kindergartens emphasize the importance of promoting children's opportunities to play in safe but challenging outdoor environments. These legal rules and regulations have maintained the Norwegian tradition of allowing children to spend time in nature through the expansion of kindergartens equipped with large outdoor areas (Kaarby \& Tandberg, 2017). Yet in everyday institutional practices, practitioners interpret regulations, risks, and situations, determining in this way children's access to the outdoors (Sandseter \& Sando, 2016). Comparative studies of kindergarten professionals' attitudes towards outdoor risky play found that Norwegian practitioners embrace a more liberal approach towards children's risk-taking. This has been discussed in light of more lenient safety regulations and a less common culture of litigation from parents and society in Norway, especially when compared with norms in Anglo-Saxon countries, as well as this country's pedagogical approaches that focus on physical development and the child's interrelationship with the environment (Sandseter et al., 2012) .

These constructions of childhood and family life around friluftsliv are present in public health practices. Helsesфstre are professionals who work at the Maternity and Child Health Care Centers and School Health Services. The former is a universal programme for families with pre-school children, which includes home visits, check-ups for the child's development, immunization, and 
health education and guidance for parents. It consists of 14 appointments that become less frequent as the child gets older. In these encounters of approximately twenty minutes long, the nurses discuss with families issues regarding the child and family wellbeing, focusing on the promotion of a good interaction between parents and children, and certain patterns of behavior based on notions of healthy habits (Andrews, 2003). These services are informed by a public health discourse dominated by psychology and social sciences that has been argued to contribute to the professionalization of socialization practices and legitimation of social control. More specifically, helses $\phi$ stre are expected to ensure "proper" child development and identify inadequate care and families at risks, working in cooperation with the Child Welfare Service (CWS).

Studies on migrant parents' experiences with Norwegian kindergartens have shown that the focus on outdoor play comes as a surprise for them (Johannessen, Odden, Ryndyk, \& Steinnes, 2013; Odden, 2016). How this group of parents navigates risk discourses as they pertain in public health has remained unexplored. We now turn to discuss the methodology used, and then the findings of our work with migrant parents, as we developed our investigation of these issues further.

\section{Methodology}

In the analysis presented below we draw on data from a doctoral project that comprised Focus Group Discussions (FGDs) and interviews with parents from Spain, Italy, Portugal and Greece about a range of aspects of raising their children (Herrero-Arias et al., 2020a, 2020b). Family leisure and outdoor play emerged as key areas of informants' interactions with professionals and, for this article, we extracted and analysed the data related to parents' discussions about this aspect of parental experience. 
The study participants were recruited through: advertising on Facebook groups (8); the personal network of the first author (5); gatherings organized by the migrant communities in Norway (4); and snowball sampling (3). Recruiting informants through Facebook and snowball sampling is used frequently by social scientists (Crush et al., 2012). This strategy excludes some groups like individuals without Internet access and older populations (Chan and Popov, 2015). Our target group was young and middle-aged adults who use communication technologies in their everyday. Migrants often use social media to establish relationships and exchange information across countries (Dekker and Engbersen, 2014). The Facebook groups we approached are platforms in which prospective migrants, migrants, and nationals exchange ideas and information, post advertisements, and make announcements about relevant events happening in Norway and Southern Europe, as well as events arranged by the online community itself. Overall, its members share a common language and interest in Norway and Southern Europe, and represent a heterogeneous group regarding their reasons for migrating and their gender, age, and social class.

Our sampling approach resulted in 15 mothers and five fathers taking part in the study, which was considered to be an adequate sample as the purpose of the study was not to compare responses by gender but to explore the complexities of experiences of parenting in migration. Participants had one to three children, aged from eight months to 17 years, and lived in three Norwegian municipalities. They were diverse in terms of age (from approximately 30-45 years old), education level (from uncompleted high school to doctoral education), and job occupations (from unskilled manual work to managerial positions). Apart from one mother whose son was attending secondary school and a couple whose daughter was about to enrol in kindergarten, all participants had experiences with Norwegian preschool education. Furthermore, three mothers worked as kindergarten assistants and another as a cleaner in a kindergarten. As for their experiences with 
helsesфstre, all informants were familiar with the Norwegian Health Centres. Most participants had had experiences with neonatal and maternal care, and the School Health Service in Norway.

Data were collected in 2017 through two FGDs and 14 in-depth interviews. FGD is a method that explicitly uses interaction to explore the predominant social norms, values, and experiences (Krueger and Casey, 2015). In our study, each FGD lasted 120 minutes and was conducted with mothers who were asked to reflect on raising their children in Norway and meeting other parents and professionals. Interviews followed a narrative approach that encourages interviewees to tell a story about significant events in their lives and social contexts, generating detailed accounts that bring a deeper understanding of individuals' experiences and opinions, and the socio-historical context in which these are embedded (Jovchelovitch and Bauer, 2000). Interviews were individual apart from two that ended up being with couples. Questions were open and exploratory, addressing interviewees' family backgrounds, life prior to migration, critical turning points in their lives like unemployment and becoming parents, transitions, and life after migration. In addition, the first author participated in gatherings organized by the Spanish and Italian communities in Norway and in Facebook groups used by Southern Europeans living in this country. These additional windows into migrant parents' meaning-making provided background knowledge about the Southern European community in Norway to better contextualize and interpret the data. Following the guidelines of the Norwegian Data Protection Official, which approved the research project, written informed consent was obtained from participants. To ensure confidentiality, pseudonyms were used and detailed information about personal characteristics and family structure were left out.

Being a Southern European migrant herself, the first author had an "insider" position that facilitated trust building and that required critical reflexivity regarding the possibility of reinforcing participants' othering processes by identifying their belonging to an in-group opposed to Norwegian parents and professionals. However, participants frequently treated the first author as an "outsider" 
because she was not a parent herself. This entailed detailed accounts of their experiences with professionals to help her understand such unfamiliar encounters for her. To mitigate the possible biases that the researcher's insider position could have implied, the co-authors, who were neither Southern Europeans nor migrants, participated in the analytical process.

Data were transcribed verbatim, translated into English, and imported into qualitative analysis software (NVivo) which helped to organize and code the data set. The FGDs and interview transcripts were thematically analysed following Braun and Clarke's (2006) six steps-model. We paid particular attention to how parents talked about their experiences with professionals' advice on family leisure and outdoor play, and how they responded to discourses of risk in this context. As we go on to elaborate, parents responded to and negotiated these interactions in three main ways. These were shaped by parents' perceptions of the distinctive aspects of Norwegian constructions of risk. We discuss these differing responses in turn, but first situate them through discussion of how the participants perceived and understood these constructs.

\section{FINDINGS}

\section{Negotiating risk as a migrant parent}

Migrant parents stressed the difference they experienced between Norway and their countries of origin regarding professional advice about parenting and family life. They highlighted the greater focus on contact with nature encountered in their host country:

Isabel: In kindergartens, children are used to being outdoors

Nieves: Norwegians are born with that

Isabel: It's cultural, it's in the kindergarten curricula

Nieves: Maybe it's also like that for a child who lives in the mountains in Spain because he has trees nearby. The relationship with nature is very different here. They are very close to nature. 
Isabel: Yes, because it's nearby (FGD2)

Informants made sense of the importance given to outdoor play in Norwegian kindergartens by associating culturally informed images of Norwegians as "nature-loving people" with this country's unpopulated landscape and geography. Expectations about children were also presented as connected to the characteristics of physical space in the city. Marta commented:

This city isn't extremely dangerous. My hometown is the same size and I've never ever seen a 7-year-old walking alone to school because there are many cars. Here, you are expected to let your child walk to school (FGD1).

Norwegian childrearing norms were, in this way, both very apparent to these parents and rationalised as outgrowths of "Norway" as a country. Their account of professionals' interpretations of these norms, however, communicated a clear sense that they had attained moral and political dimensions in constructions of "good" childhood and "good" parenting. Nieves said, '... if you are parents who are at home all day, the kindergarten professionals will give you a dirty look because the child must be taken outdoors. Luft [air in Norwegian], so much luft is very important' (2FGD).

Our informants not only indicated that 'dirty looks' could comprise part of the moral validation of the importance of the outdoors. They also located the clash in risk perceptions and constructions of childhood in socioeconomic and political contexts. Professional advice and practices promoting outdoor play and family leisure were understood to be connected to precepts about the development of skills like creativity, autonomy, and participation, considered crucial to children thriving in Norway. Linda contrasted the way Norwegian and Greek approaches to kindergartens reflected these wider contexts:

In kindergarten, they prepare kids to be part of a social-democratic society, whereas in Greece, they prepare them to be in a "dog-eat-dog" world: "you have to 
be best, you have to live by yourself and with your family because no one else will do it for you". That is how we raise children in Greece from kindergarten, with classes, contests.... whereas here, "you are going to be a member of society that is going to look after you, and you have to be like everyone else", so children play all day and learn to share, do things together... (2FGD)

Overall, then, parents communicated a clear experience of being parents in a country with a particular set of childrearing norms. They understood these as deeply embedded in wider social structures, and as having explicit moral dimensions when expressed in professionals' practices. We now explore how migrant parents navigated, negotiated, and contested professional advice on family leisure and children's play.

\section{Contesting discourses of risk: disputing professional advice or looking for a compromise}

This first theme refers to accounts where informants questioned and resisted professional discourses of risk. Strong contrasts were drawn between normative assumptions about what was "good for children", as associated with a home culture, and those experienced in Norway, and a double-bind seemed explicit when migrant parents discussed these. This emerged in different ways, first when parents talked about their initial encounters with Norwegian kindergartens. Accounts of strong emotional responses, primarily fear, characterised discussion of having to allow their children to engage in activities that involve heights, high speed, and the use of tools like knives, considered dangerous in Southern Europe. Motivated by their assessments of the risks that outdoor play could pose to children, like injuries or sickness, they contested Norwegian professional opinion. The following, from María Jesús, was a typical account, especially among informants with working-class occupations:

Kindergartens are completely different from the Spanish ones; you say, "What is this? A goat's farm?" It's so different that you get scared. One-year-old children on top of a hill, with stones, dragging, everything filled with mud. It's terrible. I was 
so scared, "They cannot control the children, so small, on the street all day, children who aren't used to being on the street". I also reacted to another thing. You see the kids dripping [with water]. "OMG what if they get a pneumonia and nobody notices it?" All day outdoors, raining. I remember one day it was raining a lot, and, of course, they went on an excursion. I went home crying so worried about my child feeling cold.

Professional norms were also contested in less emotional terms, as this discussion between three mothers suggests. Linda began by recounting this interaction:

The helsesфster asked us what we did during the winter holidays... I thought about Norwegian families going to their cabins to ski, and well, it's true that outdoors activities are perfectly suitable to do as a family, whereas the other social activities that we have in Southern Europe like going to dinner, doing things after work don't exist. You come home earlier than you would [if you live] in Greece, but what can you do?

Sabrina's response was, "Yeah, because the child has to go to bed at 7" and Agnese replied, "It seems that the more you go to the mountains, the better parent you are".

It appeared very apparent in this exchange that these mothers felt the operation of a clear measure of good parenthood in "going to the mountains" and early bedtimes for children. As the conversation proceeded, a rejection of the perceived child-centred ethos underpinning these measures and validation of an alternative, preferable understanding of child-rearing emerged:

Sabrina: In Norway, being a good parent means to allocate a chunk of your time to your children. "On Sunday, we do activities with the kids, and we spend money". Because normally to do activities you have to spend money, unless you go for a walk in the woods, while in Italy it's more like kids.....

Agnese: They are more part of the activities of the parents anyway.

Sabrina: We are more collective, the children are always with us, whatever we do, so we don't need to allocate time to them.

Agnese: You aren't doing anything specific for children, you do activities with children that you'd normally do, like you'd visit your family, they'd play with their cousins. 
Sonia: Neighbours.

Sabrina: Here, it has to be planned around the child

Agnese: In Italy, you don't have to plan ... it's more like a natural thing, ... you

are going out, you have dinner and the children are with you. In Norway, that would never happen because children go to bed at $7.30 \mathrm{pm}$, and if you bring your children to dinner with you, you are seen as a horrible parent because you drink beer in front of your children, you are a horrible person.

Linda: You keep them up late, you know the sleeping cycle from the helses $\phi$ ster? (FGD1)

They described their origin countries' approach towards family leisure as "collective" meaning that the time families spend together is experienced as "natural" because parents do not plan in advance which activities they are going to carry on to ensure these are focussed on the child. This was assessed as a positive approach because it was not highly demanding for parents, and it would promote positive outcomes for children like the development of social skills, fun memories, and closeness in family.

The language used suggests the parents perceived a clash in professional understandings of "proper" family leisure between Norway and their countries of origin, involving clear and explicit moral judgements about their parenting. References to being thought of as a "horrible person" and "horrible parent" accompanied discussion of professional responses to Southern European norms of later bedtimes for children, and consuming alcohol in front of them. Indeed, in their encounters with professionals, informants frequently discussed how irregular or late bedtimes (after $7 \mathrm{pm}$ ) were seen as a risk to their children's healthy development and the expectation that they must protect their children from these dangers by ensuring quality sleep. Parents expressed their disagreement with this measure of the quality and worth of their parenting, discussing the value of communal evening activities where children are together with adults. 
Carmen: In our wedding, Norwegians were shocked to see children, "how can you bring a child to a party?" [They said]

José: Because for them parties are like Sodom and Gomorrah, they get so drunk. Carmen: Exactly, whereas we don't get wasted but share the fun with kids José: It's nice for children to be with their family at their auntie's wedding.

Contestation of professionals' risk perceptions were particularly marked in discussion about adults drinking alcohol. Informants often questioned that moderate adult alcohol consumption was a risk from which they should protect their children and justified their decisions to include them in activities that involved this practice by referring to legitimate images of "good" parents. They described "good" parenting as appropriate modelling, meaning teaching the child social and cultural norms through one's behaviours; as Sonia put it:

You just show them [children] that it's something natural, something you have to be reasonable about, something you can do when you are mature, so when they are older, they won't end up like Norwegians who drink to get drunk.

Alcohol consumption in front of their children was constructed as a part of, not abrogation of, good parenting. It was discussed as a way to show children informed patterns of moderate and nonproblematic social drinking, which would protect them from dangerous drinking patterns observed in Norway. Migrant parents referred to their own childhood experiences with exposure to adults' social drinking and highlighted that these did not negatively influence their development.

While contesting expert-knowledge in this context, participants seemed, however, highly aware of professionals' moral judgements about their role as risk-managers based on assessments of their lifestyle choices. This influenced whether they would openly question professional advice. For instance, in topics like outdoor play, migrant parents frequently expressed that they felt they could show their disagreement with professionals without being categorized as "bad" risk-managers. This 
motivated their attempts to "meet in the middle" by coming to a compromise in which each party gives up part of their demand:

Agnese: When my daughter started kindergarten, we were shocked about the idea that kids in Norway sleep outside in the pram. I reacted to that, I spoke to the staff, we considered that she could sleep inside where there were few children. You try to find a compromise because you can't change Norwegian society, and you don't want your child to be that different.

When informants described an experience of negotiation, they also indicated an awareness of their "marginal" position in the host society. This seemed to mean that in relation to some definitions of good parenting they would not seek a compromise, because they predicted that in practice it was easier for them to adapt, or appear to do so, as we now discuss.

\section{Feigning cooperation}

Migrant parents often shared that some kinds of expert-knowledge about children and family life were considered non-negotiable, for instance advice on alcohol consumption and family leisure. Their accounts of their experiences with professional advice on this topic came accompanied by feelings of misrecognition of own knowledge. Fear that professionals would position them as a risk to their children and make a referral to the CWS came up more strongly in the interviews with parents with working-class occupations. Sonia contrasted how she would differentially negotiate discussing concerns about knives in kindergarten and adults drinking alcohol:

You decide to have a discussion on something with a professional depending on the subject and the possible consequences. Because if it's just an opinion, "I'm afraid that my child uses a knife in kindergarten", then, it's ok. You have your opinion. I have mine... but if the professional is going to do something because we disagree and he doesn't like the way I do things, then, depending on how much power the professional has, if there is a process, a mechanism they can initiate against 
me...Usually, we understand each other and find a middle-point, but with the alcohol thing, I wouldn't discuss with them.

María Jesús discussed her feelings of shock and fear relating to professional power when she commented in this exchange about her 'naivety' in disclosing her decision to bring her child to a local festival in Spain:

María Jesús: We went to Spain when the child was 3 months, it was our village's festivity, and we stayed as long as we wanted. The child [was] in the pram. We weren't going to the disco, of course not; we sat in a terrace having some drinks with friends. When I came here, she [the helsesøster] asked me how it was. I, naive of me [said], "The festival was great". "The child wasn't at the Fair, right?" and I didn't know what to say. "Why has this woman got shocked because we...?" The child was sleeping in the pram! She started with the sleeping schedules again. Researcher: Why did you say that it was naïve of you to tell her about the fair? María Jesús: Because maybe she doesn't like it and thinks we are bad parents. Here, alcohol and children present is a terrible thing and the helses $\phi$ ster has power, she can call Child Protection.

Incorporating their children into their free time with other adults was a practice that participants very clearly associated came with a high cost, and they would not openly contest its delegitimation as part of child-rearing in their encounters with professionals. For Isabel and Miriam, this rule about parenting was 'non-negotiable':

Isabel: Going out and having alcohol in front of your children? That is nonnegotiable. If in kindergarten, they ask you what you did during the weekend, you just say that you went hiking, but don't say that you invited some friends over for dinner or went at a restaurant with the kids? And alcohol? Miriam: Don't say that, they wouldn't approve it (FGD2)

Many informants shared their experiences of internally disputing and rejecting professional advice and practices but complying. They seemed aware of being in a marginal position from which 
it was not possible to challenge the host society's dominant views on childhood and parenting, so as Inés put it, "When in Rome, do as the Romans do":

You meet with the kindergarten staff and other parents on a fantastic excursion, well, all bring tea, coffee, because a beer? No! For us, "Countryside [means] big meal and beer". It's in the Spanish culture. We opened our beer can and saw everybody drinking coffee. They didn't say anything but looked at us with a face that we wanted to die. You immediately realise. "Let's see, here there is something going on, this is bad". I've learned that "When in Rome, do as the Romans do". If you meet the helsesøster, "We don't have any beer in front of the child". You must shut up and go on, don't get involved, don't question them, because you have so much to lose.

In such cases, participants indicated they would pretend they agree with professionals' risk assessments and advice. Distrust and deceit in this way comprised central parts of their interactions with professionals and a means through which they addressed the double-bind of contrasting assumptions about what makes a good parent.

\section{Accepting discourses of risk: collaborative or compliant relationships}

At the same time, informants frequently shared having experienced adaptation to some professional advice and even endorsing their approach. This experience was discussed in accounts of experiences with outdoor risky play, across time. Migrant parents discussed that the change in their responses was motivated by positive experiences with their eldest child. As Agnese shared, "when my youngest was born, I already knew how kindergartens are, and my eldest never got injured or had any problems, so I just accepted my child would be all day outdoors".

Informants discussed that in Norway, professionals promote outdoor play because they prioritize the skills children could learn from it over the risks that it might pose to their physical 
safety. These parents discussed how their feelings about knives and axes modified, in line with their experience, to a point of appreciating the development of self-sufficiency in their children:

Rocío: I remember how shocked I got when I started my job in the kindergarten and saw 4 year-old children going on an excursion far away, and they took fold able knives. [...]

Miriam: They give small axes to 5 -year-old children

Rocío: I thought, "I'm going to get a heart attack", the knives were so sharpened. Miriam: There's always somebody supervising but nobody approaches the children, "Don't take this! Be careful!"

Rocío: Yes, because for them what matters is that the child learns and has fun, it doesn't matter if the child gets dirty, a bit injured. [...]

Miriam: In Spain, the kindergarten staff are more concerned about the child behaving himself, well, about the mother being satisfied with their work because the child got home clean, well-combed...

Isabel: Smelling of cologne!

Rocío: In Spain, mothers protect children so much against the cold, warmth (...). Here, children become stronger, they come wet from the school and they have to take the clothes off, my daughter came crying because the snow penetrated the clothes, "Mum, I had to change all the clothes, and I was alone at home!" Nieves: More self-sufficient (2FGD).

The positive outcomes that outdoor play appeared to generate for their children meant they evaluated practices in their cultures of origin more critically, and the double-bind was resolved through an acceptance of the Norwegian approach to risk. However, among the group of informants holding middle-class occupations, we found some parents who reported that they already agreed on the benefits of outdoor play prior to migrating, and appreciated the Norwegian professional practices in contrast to those of their countries of origin, which they were already sceptical about:

João: My son was sick with laryngitis, coughing, at the kindergarten. They took him outdoors, but I didn't see it wrong, I think it's good. It helps him to develop the creative part, freedom [...]. I like this approach. For this reason, I feel I fit here better than in Portugal. 
Migrant parents did not always embrace educational practices promoting outdoor play in collaborative relationships with professionals. As María Jesús explained it, in some cases, migrant parents would adopt a permissive attitude towards outdoor risky play when they thought there was not any other alternative left for their children.

You get used to it, you don't have any alternative... It's difficult, to be honest, it's

hard, but I think that once you are inside, you say: "I have to give in, I'm already here", so I gave in. I cannot do anything else. Either you take him to the kindergarten, and you work, or you don't work and stay at home with the child.

These accounts were more common among parents who did not hold a bachelor's degree and did manual work. These parents stressed the clash they experienced in risk constructions and ideas of skills children should acquire through formal education. They experienced also the process of adaptation to professional practices as an accommodation partially borne from financial necessity. Parents complied with the Norwegian approach, and had to sublimate their own culturally informed risk perceptions.

\section{DISCUSSION}

In a previous article (Herrero-Arias et al., 2020b), we analysed informants' narratives of migration to Norway. Migrant parents articulated their migration stories around their aspirations for 'involved parenthood' in a country with policies that they perceived to be ones aiming to support their family projects. Based on this, we expected to find that when informants discussed their encounters with professionals, they would share experiences of feeling supported in their parenting efforts. Yet professionals' practices and advice about outdoor play and family leisure were mostly experienced by the migrant parents as not open for discussion and, therefore, not always supportive. The most dominant feature of parental experience was a perception of moral judgement of behaviours and lifestyles associated with Southern European cultures. Indeed, the extent to which this was the case, 
and the way our informants discussed an experience of being judged and found wanting in their parenting, came as a surprise to the authors.

In line with previous studies (Johannessen et al., 2013; Odden, 2016), our informants were surprised that children falling, getting dirty or wet were not considered dangerous by Norwegian professionals. Migrant parents clearly experienced a contradiction between understandings that influenced the approach of those working in kindergartens in their countries of origin, and that in Norway, and they had to find ways of managing this, which for some gave rise to difficult emotional states like fear that their children get injured. Across the data, boundaries between risk constructions in outdoor play seem to be understood as cultural or national. However, following previous literature on risk (Aamann \& Dybbroe, 2018; Montelius \& Nygren, 2014), we argue that class can be relevant as a means of explaining this difference. In Norway, parenting norms are in line with intensive parenting, an ideology moulded by middle-class values and notions of children's vulnerability (Bendixen and Danielsen, 2018). Considering this, unsurprisingly, we found that informants with middle-class backgrounds positioned themselves closer to notions of risk-management encountered in Norwegian kindergartens. Among this group of parents, we found experiences of gratitude for a professional practice that supported own understandings of "good" childhood and of the skills that children should acquire to thrive. Parents with working-class occupations contested professional advice on outdoor play more and stressed how challenging it was to find ways around this practice. However, it was in this aspect of parental experience that we found most evidence of accommodation and even support for the practices based on positive experiences, and a partial resolution of the double-bind across time.

To make sense of the difference in risk discourses, informants reflected on how survival is understood in the host and origin countries. In Norway, professionals promoted outdoor activities 
through which children acquire skills like creativity, independence, teamwork, and participation, which are needed to thrive in a modern, democratic and egalitarian society. Migrant parents discussed that the adult-oriented activities typical of kindergartens in their countries of origin mirror the set of skills that are thought to ensure children's futures in Greece, Portugal, Italy, or Spain, like good manners and discipline. This reflexivity about differences in approach and the reasons for it led some to express support for practices in Norway.

Informants identified a larger clash, however, in constructions of childhood and parenting underpinning risk discourses, and this influenced more hostility towards and criticism of experience with professionals. In line with Nilsen's findings (2008), our participants discussed how childhood is constructed as a social category separated from adulthood in Norway. They recognised through their experience that the State, through its institutions like kindergartens, is responsible for ensuring children's good childhood, understood as a childhood unpolluted by the adult world. Moreover, because ideas of "good" childhood reflect core cultural values, in Norway, children are seen as key actors for the reproduction of the traditional cultural values and practices of nature, which are central to this country's national identity (Gullestad, 1992, 1997). Migrant parents discussed how the focus on outdoor activities mirrored processes of cultural reproduction, particularly, the Norwegian State's responsibility to promote acquiring skills needed to experience nature (Nilsen, 2008). As previously discussed (Herrero-Arias et al., 2020b), migrant parents negotiated their and their children's belonging to the host society through the performance of "Norwegian" practices, like outdoors activities. In this context, parenting emerges as a citizenship practice (Longman, De Graeve, \& Brouckaert, 2013). Although informants usually presented the outdoors as a positive practice for their children development, they were also aware of being in a marginal position from which it was difficult to challenge the dominant discourse without consequences, like being regarded as "the others". 
Following Johansen (2019), we argue that the notion of "double-bind" is useful to unpack such an experience of marginality. The Palestinian parents in Johansen's ethnographic study navigated conflicting parenting norms from the Danish State and from their community of origin. Caught in this double-bind position, meeting professionals' demands led to parents' exclusion in relationships with their families and the Palestinian community. In our study, contesting professional advice could reinforce migrant parents' experience of othering in Norway. At the same time, the fulfilment of professionals' expectations prompted to informants' distance from lifestyle choices associated with their cultures of origin, which involved sacrificing their social life and children's socialization with other adults, more stress and time-consuming and costly activities.

Informants also identified wider societal preoccupations about the socialisation of children to adult roles in professionals' advice. They interpreted their experience as one influenced by a process in which adults' anxieties about modern life were being imposed onto children (Bristow, 2014). While they identified emphasis on nature, the mountains, healthiness and the outdoors as a discourse of fun, freedom or adventure, they also discussed the presence of a discourse of worry, which included rules for how children should be parented by being protected from risks from the adult world. These understandings of good childhood and parenting came as a surprise for them, because in their countries of origin parents are expected to facilitate their children's socialisation into the adult world, not protect them from it.

Parents experienced this discourse of risk as powerfully moralised in their encounters with professionals, sharing experiences of professionals who they considered judged their parenting, based on how well they protected their children from legitimated risks. In line with Aamann and Dybbroe's (2018) findings, our informants discussed how professionals typically recognised risks related to their lifestyle choices as they were identified as risks to children's wellbeing. Leisure 
activities that involved late or irregular bedtimes, moderate adult alcohol consumption, or sedentariness were constructed in this way and parents discussed how professionals viewed these as signs of irresponsible parenting. In contrast, migrant parents contested this professional account of family leisure, and they justified their decisions, like bringing their children to local festivities, by referring to a different constellation of legitimated notions of "good" parent as "good" risk-manager (Lee, 2007). Informants stressed that it was their duty as parents to protect children and to be a good role model for them. Moderate drinking in front of children was constructed as a practice that was not dangerous but, rather, would teach them a cultural pattern of social interaction. They also highlighted their responsibility to ensure their children have good memories and develop social skills through interaction with others. These contestations of such notions of risk-management were common across the data. However, most migrant parents who experienced their encounters with helsesфstre as confusing and even frightening because of an awareness of possible interventions from CWS had working-class backgrounds. This experience contrasts with that of parents with middleclass backgrounds, who contested professional views on family leisure but seemed to have more knowledge about how to present themselves as good parents in front of professionals.

Parents thus experienced their decisions about family leisure and children's play as a "measure of parenting" that led to two forms of positioning. On the one hand, informants felt they might be positioned as "good" parents, able to successfully manage the legitimated risks to their children's upbringing with the help of professionals. "Good" parents were also expected to balance their children's risk-taking through motivating them to engage in activities constructed as positive for their development, like outdoor play. On the other hand, informants experienced a clear professional positioning of the parent who allows a child to stay up late with other adults, or be around adults drinking socially, as explicitly irresponsible. This emerged as the major source of 
tension, given parents' strong sense of the importance of having children involved with, not separated from, adults as part of everyday life.

Our analysis identified that informants openly contested professional discourses when they had confidence that they were not going to be positioned as irresponsible parents for their opinions and decisions. This would be the case in topics like children's outdoor naps and play. Furthermore, when migrant parents felt that their opinions were valued and professionals were open to "meet in the middle", they tried to reach a compromise. As we have noted, some participants discussed the benefits of the Norwegian approach towards family leisure and children's play, and their decisions to embrace some of the advice from professionals especially after having positive experiences with the first child. As Odden found out in her study on Polish mothers in Norway (2016), socialisation over time was an important factor shaping parents' responses to professional advice.

While migrant parents recognized the benefits of Norwegian ideals of family leisure, they were, however, critical of the high demands it put on them in contrast to those ideals from their countries of origin. Rather than just spending time with their children, they experienced professionals seeing them as responsible for planning and performing activities that would teach children values and skills valued in Norway. These notions of purposive leisure differed from what participants defined as "collective" leisure, the typical approach from their countries of origin, where parents include their children in the activities they do in their free time. Their experiences with the Norwegian family leisure ideal were characterized by feelings of frustration and lack of enjoyment, which contrasts with Norwegian parents' experiences of outdoor family leisure as a space free of obligations (Baklien, Ytterhus, \& Bongaardt, 2016). In Norway, migrant parents experienced more family-friendly working conditions that made it possible for them to have more time with their children. However, due to the dominant notions of family leisure, informants experienced their free 
time as a burden to some extent, in the sense that they felt the expectation on them to spend material resources and time doing child-centred activities.

When migrant parents perceived that professionals misrecognized and devalued their knowledge and positioned them as irresponsible parents, they did not openly contest professional advice but decided to "play along" or comply with it. This strategy was also prompted by parents' feelings of being in a marginal migrant position, from which it was impossible to challenge the dominant discourse, and by their fears of CWS, which appeared reinforced by public discourses representing the meeting between this institution and migrants as problematic (Hollekim et al., 2016). Although they contested risk discourses that portrayed adults drinking alcohol in front of children as risky for their children in the context of our research, informants decided to feign agreement or comply with professionals.

\section{Conclusions}

The purpose of this paper was to discuss the experience of Southern European migrant parents living in Norway, to further explore the workings of a double-bind in parental experience. The research, focussed on parents' encounters with kindergarten professionals and community health nurses, gives weight to the salience of this term to capture an important dimension of parenting culture. Our informants communicated explicitly ways in which their parental role as risk-managers left them in a double-bind.

Our findings suggest this double-bind operates powerfully in the context of migration, but with differences in how parents managed its demands. Tensions in contrasting ideas about responsible kindergarten practices meant some parents experienced troubling emotions when they encountered being considered as over-protective parents. This tension, however, emerged as 
relatively easier to accommodate and negotiate than what emerged as a profound difference in understandings of childhood and adult responsibility, and so marked conflicts around family leisure and lifestyle. These were addressed primarily through feigning compliance and deceit in interactions with professional and associated manifest low levels of trust and common ground. Indeed, fear of reprisals was a feature of this aspect of the double-bind. An approach that appears to legitimise intervention in the lives of parents, which is experienced as oppressive, as reported here, is the aspect of the double-bind that most obviously deserves further attention from research, given its apparently troubling impact on parental experience. Our analysis did not directly consider gender as part of the workings of the double-bind and this should be explicitly addressed by future studies. To better understand constructions of risk-management and of responsible parenting, further research on parents' reactions to parenting ideals informing professional practices and discourse is needed. 


\section{References}

Aamann, I. C., \& Dybbroe, B. (2018). 'So under “cause for concern”, I'll write that...'class, parenting and risk prevention in public health practices in schools: a question of moral value? Health, Risk \& Society, 20(5-6), 259-275.

Aasen, W., Grindheim, L. T., \& Waters, J. (2009). The outdoor environment as a site for children's participation, meaning-making and democratic learning: examples from Norwegian kindergartens. Education 3-13, 37(1), 5-13.

Allin, L., West, A., \& Curry, S. (2014). Mother and child constructions of risk in outdoor play. Leisure Studies, 33(6), 644-657.

Andrews, T. (2003). Radical changes or traditional approaches in a different guise? An analysis of the Norwegian mother-child service. International journal of health services, 33(2), 219-234.

Baklien, B., Ytterhus, B., \& Bongaardt, R. (2016). When everyday life becomes a storm on the horizon: Families' experiences of good mental health while hiking in nature. Anthropology \& Medicine, 23(1), 42-53.

Bateson, G., Jackson, D. D., Haley, J., \& Weakland, J. (1956). Toward a theory of schizophrenia. Behavioral science, 1(4), 251-264.

Bateson, G. (1972). Steps to an Ecology of Mind: Collected Essays in Anthropology, Psychiatry, Evolution, and Epistemology. University Of Chicago Press.

Bendixsen, S., \& Danielsen, H. (2019). Other people's children: inclusive parenting in a diversified neighbourhood in Norway. Ethnic and Racial Studies, 42(7), 1130-1148.

Braun, V., \& Clarke, V. (2006). Using thematic analysis in psychology. Qualitative Research in Psychology, 3(2), 77-101.

Bristow, J. (2014). The double bind of parenting culture: helicopter parents and cotton wool kids. In E. Lee, J. Bristow, C. Faircloth, \& J. Macvarish (Eds) Parenting culture studies (pp. 200-215). Springer.

Brussoni, M., Gibbons, R., Gray, C., Ishikawa, T., Sandseter, E.B.H., Bienenstock, A., Chabot, G., Fuselli, P., Herrington, S., Janssen, I. \& Pickett, W. (2015). What is the relationship between risky outdoor play and health in children? A systematic review. International journal of environmental research and public health, 12(6), 6423-6454.

Chan, F. Y. W., \& Popov, V. (2015). Facebook as a research tool for the social sciences. American Psychologist, 70(6), 543-556.

Crush, J., Eberhardt, C., Caesar, M., Chikanda, A., Pendleton, W., \& Hill, A. (2012). 16 Diasporas on the web: new networks, new methodologies. Edward Elgar Publishing, UK.

Dervo, B. K., Skår, M., Köhler, B., Øian, H., Vistad, O. I., Andersen, O., \& Gundersen, V. (2014). Friluftsliv i Norge anno 2014-status og utfordringer [Outdoor life in Norway in 2014 -status and challenges] Norwegian institute for nature research, NINA Rapport 1073. 98 pp.

Dekker, R., \& Engbersen, G. (2014). How social media transform migrant networks and facilitate migration. Global Networks, 14(4), 401-418.

Fullagar, S. P., \& Harrington, M. A. (2009). Negotiating the policy imperative to be healthy: Australian family repertoires of risk, leisure, and healthy lifestyles. Annals of leisure research, 12(2), 195215.

Furedi, F. (2008). Paranoid parenting: Why ignoring the experts may be best for your child. Continuum.

Gard, M., \& Wright, J. (2005). The obesity epidemic: science, morality and ideology. Abingdon: Routledge.

Guldberg, H. (2009). Reclaiming childhood: Freedom and play in an age of fear. Routledge.

Gullestad, M. (1992). The art of social relations: essays on culture, social action and everyday life in modern Norway. A Scandinavian University Press Publication. 
Gullestad, M. (1997). A passion for boundaries. Reflections on connections between the everyday life of children and discourses on the nation in contemporary Norway. Childhood-A Global Journal Of Child Research, 4(1), 19-42.

Hays, S. (1998). The Cultural Contradictions of Motherhood. Yale University Press.

Herrero-Arias, R., Hollekim, R., Haukanes, H., \& Vagli, Å. (2020a). The emotional journey of motherhood in migration. The case of Southern European mothers in Norway. Migration Studies, mnaa006.

Herrero-Arias, R., Hollekim, R., \& Haukanes, H. (2020b). Self-legitimation and sense-making of Southern European parents' migration to Norway: The role of family aspirations. Population, Space and Place, e2362.

Hoffman, D. M. (2010). Risky investments: Parenting and the production of the 'resilient child'. Health, Risk \& Society, 12(4), 385-394.

Hollekim, R., Anderssen, N., \& Daniel, M. (2016). Contemporary discourses on children and parenting in Norway: Norwegian Child Welfare Services meets immigrant families. Children and Youth Services Review, 60, 52-60.

Johannessen, Ø. L., Odden, G., Ryndyk, O., \& Steinnes, A. (2013). Afghans and early childhood education in Norway: a pilot project. SIK Report Series, vol. 2, https://vid.brage.unit.no/vidxmlui/handle/11250/2608589

Johansen, M. L. E. (2019). Fraught parenting: Immigrant parents' chronic double-bind in Denmark. Ethnography, 1466138119892018.

Jovchelovitch, S., \& Bauer, M. W. (2000). Narrative interviewing. Qualitative researching with text, image and sound, 57-74.

Knaak, S. J. (2010). Contextualising risk, constructing choice: Breastfeeding and good mothering in risk society. Health, Risk \& Society, 12(4), 345-355.

Krueger, R. A., \& Casey, M. A. (2015). Focus groups 5th ed.

Lee, E. (2007). Health, morality, and infant feeding: British mothers' experiences of formula milk use in the early weeks. Sociology of health \& illness, 29(7), 1075-1090.

Lee, E. (2008). "Living with risk in the age of 'intensive motherhood': Maternal identity and infant feeding." Health, Risk \& Society 10(5): 467-477.

Lee, E., Macvarish, J. and Bristow, J. (2010). Risk, health and parenting culture. Health, Risk \& Society, 12(4): 293-300

Lee, E. (2014). Introduction In E. Lee, J. Bristow, C. Faircloth, \& J. Macvarish (Eds), Parenting culture studies (pp. 1-22). Springer.

Longman, C., De Graeve, K., \& Brouckaert, T. (2013). Mothering as a citizenship practice: an intersectional analysis of 'carework'and 'culturework'in non-normative mother-child identities. Citizenship Studies, 17(3-4), 385-399.

Montelius, E., \& Nygren, K. G. (2014). 'Doing'risk, 'doing'difference: towards an understanding of the intersections of risk, morality and taste. Health, Risk \& Society, 16(5), 431-443.

Nilsen, R. D. (2008). Children in Nature: Cultural Ideas and Social Practices in Norway. In A. James \& A. L. James (Eds.), European Childhoods: Cultures, Politics and Childhoods in Europe (pp. 38-60). London: Palgrave Macmillan UK.

Odden, G. (2016). They assume dirty kids means happy kids'. Polish female migrants on being a mother in Norway. Miscellanea Anthropologica et Sociologica, 17(3), 51-69.

Pedersen Gurholt, K. (2008). Norwegian friluftsliv and ideals of becoming an 'educated man'. Journal of Adventure Education \& Outdoor Learning, 8(1), 55-70.

Sandell, K., \& Sörlin, S. (2000). Friluftshistoria: från" härdande friluftslif" till ekoturism och miljöpedagogik: Teman $i$ det svenska friluftslivets historia [Outdoor history: from "a hardening outdoor life" to ecotourism and environmental pedagogy: Themes in the history of Swedish outdoor life]. Carlssons bokförlag. 
Sandseter, E. B. H., Little, H., \& Wyver, S. (2012). Do theory and pedagogy have an impact on provisions for outdoor learning? A comparison of approaches in Australia and Norway. Journal of Adventure Education \& Outdoor Learning, 12(3), 167-182.

Sandseter, E. B. H., \& Sando, O. J. (2016). "We don't allow children to climb trees": how a focus on safety affects Norwegian children's play in early-childhood education and care settings. American Journal of Play, 8 (2), 178

Shaw, S. M. (2008). Family leisure and changing ideologies of parenthood. Sociology Compass, 2(2), 688-703.

Shaw, S. M., \& Dawson, D. (2001). Purposive leisure: Examining parental discourses on family activities. Leisure sciences, 23(4), 217-231.

Kaarby, K. M. E., \& Tandberg, C. (2017). The belief in outdoor play and learning. Journal of the European Teacher Education Network, 12, 26-36

Thelen, T., \& Haukanes, H. (2010). Parenting after the Century of Child: Travelling Ideals. Institutional Negotiations and Individual Responses. Farnham/Burlington: Taylor \& Francis. 